\title{
FIBRIN-TYPE FIBRINOID IN HUMAN PLACENTA: A STEREOLOGICAL ANALYSIS OF ITS ASSOCIATION WITH INTERVILLOUS VOLUME AND VILLOUS SURFACE AREA
}

\author{
TERRY M MAYHEW \\ School of Biomedical Sciences, University of Nottingham, Queen's Medical Centre, Nottingham NG7 2UH, UK \\ (Accepted February 14, 2001)
}

\begin{abstract}
Stereological methods were used to examine fibrin-type fibrinoid deposition in the intervillous spaces of human placentas collected during gestation (12-41 weeks) and from term pregnancies at low (400 m) and high (3.6 km) altitude. The main aim was to test predictions about the relationships between fibrinoid deposits and either the volume of intervillous space or the surface area of (intermediate + terminal) villi. Fields of view on Masson trichrome-stained paraffin sections were selected as part of a systematic sampling design which randomised section location and orientation. Relative and absolute volumes were estimated by test point counting and surfaces by intersection counting. Apparent differences were tested by analyses of variance and relationships by correlation and regression analysis. Fibrinoid volume increased during gestation and correlated positively with intervillous volume and villous surface area. However, relative to intervillous volume, the main increase in fibrinoid occurred towards term (36-41 weeks). At high altitude, placentas contained more intervillous space but less fibrinoid. At both altitudes, there were significant correlations between fibrinoid volume and villous surface area. In all cases, changes in fibrinoid volume were commensurate with changes in villous surface area. Whilst findings lend support to the notion that fibrinoid deposition during normal gestation is influenced by the quality of vascular perfusion, they also emphasise that the extent of the villous surface is a more generally important factor. The villous surface may influence the steady state between coagulation and fibrinolysis since some pro-coagulatory events operate at the trophoblastic epithelium. They occur notably at sites of trophoblast de-epithelialisation and these arise following trauma or during the extrusion phase of normal epithelial turnover.
\end{abstract}

Keywords: placenta, fibrin-type fibrinoid, gestation, altitude, volume, surface area.

\section{INTRODUCTION}

Recently, there has been a resurgence of interest in deposits of fibrinoid within the human placenta and their differences in origin, composition and possible functional significance (Frank et al., 1994; Lang et al., 1994; Kaufmann et al., 1996; Mayhew et al., 2000). Fibrintype fibrinoid (FTF) is essentially a blood coagulation product found in the maternal intervillous space (IVS). This being so, formation of FTF will be regulated by the reactions of the coagulation cascade and the fibrinolysis pathway. The steady state is determined by the relative activities of these two pathways. Within the IVS, deposits of FTF are often associated with the surfaces of villi (Fox, 1967a, 1968, 1975; Kaufmann et al., 1996; Demir et al., 1997; Mayhew et al., 2000) and this perivillous FTF is deposited principally at sites of trophoblastic deepithelialisation (Nelson et al., 1990; Nelson, 1996; Brownbill et al., 2000; Mayhew et al., 2000).

It has been argued (Fox, 1967b, 1975) that, normally, the amount of FTF simply reflects the quality of vascular perfusion within the IVS and, in abnormal pregnancies, deposition is diminished. Morphometric studies on placentas collected at different stages of gestation have indicated that volumes of 'fibrin' and IVS both increase towards term (Aherne and Dunnill, 1966; Boyd, 1984). In contrast, there is inconsistent support for the suggestion that deposits occur less frequently in abnormal pregnancies (Aherne and Dunnill, 1966; Teasdale, 1984, 1985, 1987; Kaufmann et al., 1996; Mayhew and Sisley, 1998; Mayhew et al., 2000). In pregnancy at high altitude, the volume of FTF seems to decline despite a marked increase in volume of the IVS (Jackson et al., 1987a).

If FTF is deposited as the result of a fixed steady state between coagulation and fibrinolysis, we might predict that its volume would be directly proportional to IVS volume. In such circumstances, the volume density of FTF in the IVS space would be constant. By the same token, if FTF deposition depends principally on the surface extent of villi, we might predict a strong positive correlation between FTF volume and villous surface area. 
To test these predictions, placentas were collected from 12-41 weeks of gestation and from term pregnancies completed at low (400 m above sea level) and high (3.6 $\mathrm{km}$ ) altitudes. They were then examined stereologically so as to explore relationships between the volume of FTF and the volume of IVS and surface area of villi.

\section{MATERIALS AND METHODS}

\section{GESTATIONAL AND ALTITUDINAL STUDIES}

For the gestational study, random sub-samples of placentas were drawn from a larger set spanning 10 weeks to term (for further details, see Boyd, 1984; Jackson et al., 1992; Mayhew et al., 1994). Here, 77 placentas at 12-41 weeks were investigated. Details of the larger altitudinal study have also been presented elsewhere (Haas, 1980; Jackson et al., 1987a). Indigenous Amerindian and non-Indian women in Bolivia were included on the basis of uneventful term pregnancies (36-41 weeks). Present results are based on 24 (10 Amerindian, 14 non-Indian) low-altitude and 44 (16 Amerindian, 28 non-Indian) high-altitude subjects.

In all cases, gestational ages were assessed by the date of the last menses and checked by ultrasound and clinical examinations. Immediately after delivery, fetal or birth weights $(\mathrm{g})$ were recorded and placental weights $(\mathrm{g})$ were determined after trimming away membranes and removing blood clots. Subsequently, placental volumes $(\mathrm{ml})$ were estimated by fluid displacement or from weights and tissue densities $(\mathrm{g} / \mathrm{ml})$.

\section{TISSUE SAMPLING PROTOCOLS}

Concurrent and unbiased stereological estimation of tissue volumes and surfaces requires a sampling design which randomises section location and orientation. To this end, the basis of tissue selection was systematic random sampling (Gundersen and Jensen, 1987; Mayhew and Burton, 1988) giving all regions of the placenta an equal and independent chance of being chosen. Although not as rigorous as methods which generate IUR encounters between surfaces and test lines (Baddeley et al., 1986; Mattfeldt et al., 1990; Nyengaard and Gundersen, 1992; Howard and Reed, 1998), physical randomisation of tissue orientation was introduced prior to embedding by dicing tissue samples and allowing them to settle haphazardly in paraffin wax. Fortunately, the 3D orientations of placental villi are sufficiently variable to make it unlikely that they will compromise the isotropy requirement.
Full-depth columns of tissue were systematically sampled, immersion-fixed in formalin and embedded in wax. Sections (thickness 3-5 $\mu \mathrm{m}$ ) were stained by the Masson trichrome technique to facilitate identification of FTF deposits. Microscopical fields of view were chosen by systematic random sampling and prepared as micrographs $(\times 250)$ and colour slide transparencies $(\times 1500-2000)$. The latter were projected onto a flat screen. Magnifications were calibrated with stage micrometer scales as internal standards.

\section{STEREOLOGICAL ESTIMATIONS}

Test point and intersection counting (Howard and Reed, 1998) were used to estimate tissue volumes (ml) and villous surface areas $\left(\mathrm{m}^{2}\right)$. IVS and FTF volumes were derived from fresh placental volumes and volume densities by point counting. Villous surface areas were estimated from component densities using appropriate areal correction factors calculated using red cell diameters as an internal calibration standard. Previous studies have shown that these corrections for processing distortions are capable of generating values similar to those obtained using glutaraldehyde fixation and resin embedding.

\section{STATISTICS AND ALLOMETRY}

Group means and standard errors of means (SEM) were calculated. Comparisons between groups were drawn using analyses of variance (Sokal and Rohlf, 1981) with age and fetal gender (gestational study) and altitude, ethnic group and gender (altitudinal study) as the main factors. In the gestational study, placentas were assigned to one of five age groups: $12-17$ weeks $(n=5), 18-23$ weeks $(n=6), 24-29$ weeks $(n=15), 30-35$ weeks $(n=24)$ and 36 41 weeks $(\mathrm{n}=27)$.

Relationships between volumes $(\mathrm{V}, \mathrm{ml})$ and surfaces $(\mathrm{S}$, $\mathrm{m}^{2}$ ) were examined using untransformed data (correlation analysis) or log-transformed data (linear regression analysis). For the latter, we related $\log \mathrm{V}$ of FTF (the dependent or outcome variable) to $\log \mathrm{V}$ of IVS or $\log \mathrm{S}$ of villi (independent or predictor variables). The linear regression equation, $\log \mathrm{D}=\log \mathrm{A}+(\mathrm{B} \times \log \mathrm{I})$, identifies the dependent variable (D), independent variable (I), slope of the line (B) and integration constant (A). $\log A$ is the intercept on the $\log \mathrm{D}$ axis and $\mathrm{A}$ represents the value of D for a unit amount of I (e.g. the predicted volume of FTF for an IVS volume $1 \mathrm{ml}$ ). Conveniently, B corresponds to the exponent (or scaling factor) of the allometric relation $\mathrm{D}=\mathrm{A} \times \mathrm{I}^{\mathrm{B}}$ and this was calculated together with its SEM. 
In each statistical test, the appropriate 'null' hypothesis was rejected if the probability level, P, was less than 0.05. All tests were undertaken using Unistat statistical software (version 4.53c, Unistat Ltd, London).

\section{RESULTS}

\section{GESTATIONAL STUDY}

Fetal and placental characteristics are summarised in Table 1. Two-way analyses of variance failed to reveal any significant gender or interaction effects and so data from male and female fetuses were pooled within each age group. Over the period examined, group mean (SEM) fetal weights increased from 81 (23) g at 12-17 weeks to 3183 (122) g at 36-41 weeks. In the same age groups, mean placental weights rose from 58 (6) $\mathrm{g}$ to 442 (18) g.

Analysis of stereological data demonstrated significant increases in the total volumes of IVS and FTF and total surface areas of villi. IVS volume increased from $28(5) \mathrm{ml}$ at 12-17 weeks to 191 (9) $\mathrm{ml}$ towards term (variance ratio, $\mathrm{F}=26.97$; degrees of freedom, $\mathrm{df}=4,67 ; \mathrm{P}<0.001)$. Over the same period, villous surface area expanded from $0.9(0.1) \mathrm{m}^{2}$ to $10.8(0.4) \mathrm{m}^{2}(\mathrm{~F}=56.62 ; \mathrm{P}<0.001)$ and FTF volume from $0.5(0.1) \mathrm{ml}$ to $5.9(0.9) \mathrm{ml}(\mathrm{F}=6.47 ; \mathrm{P}<0.001)$.

During gestation, the volume of FTF correlated positively with the volume of IVS (correlation coefficient, $\mathrm{r}=0.537 ; \mathrm{df}=75 ; \mathrm{P}<0.001)$ and surface area of villi $(\mathrm{r}=0.627 ; \mathrm{P}<0.001)$. Allometric analysis of $\log$ transformed data revealed that FTF volume expanded according to the relations

$$
\text { Vfib }=0.00595 \times \operatorname{Vivs}^{1.21(0.12)}
$$

and

$$
\text { Vfib }=0.415 \times \text { Svilli }^{0.92(0.09)} .
$$

The ratio of FTF volume to IVS volume altered during gestation $(\mathrm{F}=2.62 ; \mathrm{P}<0.05)$ and, in particular, appeared to increase towards term (Table 1). In contrast, there was no significant change in the ratio of FTF volume to villous surface area during gestation. Therefore, FTF volume appeared to expand disproportionately to IVS volume and in a manner more commensurate with the growth in villous surface area.

\section{ALTITUDINAL STUDY}

Findings are summarised in Table 2. Three-way analyses of variance failed to identify any gender-related effects and so results are confined to altitudinal and ethnic differences. At low altitude, neonates had a mean birthweight of 3309 (84) $\mathrm{g}$ and mean placental weight of 458 (21) g. The placenta contained 179 (12) $\mathrm{ml}$ of IVS, $6.9(0.4) \mathrm{m}^{2}$ of villous surface and $8.5(0.8) \mathrm{ml}$ of FTF, giving an FTF volume density in the IVS of $0.050(0.005) \mathrm{ml} / \mathrm{ml}$ and a density with reference to the villous surface of $1.24(0.08) \mathrm{ml} / \mathrm{m}^{2}$.

Table 1. Fetal and placental characteristics between 12 and 41 weeks of gestation. Values are group means (SEM).

\begin{tabular}{lccccc}
\hline \multicolumn{1}{c}{ Variable } & $\begin{array}{c}12-17 \text { weeks } \\
(\mathrm{n}=5)\end{array}$ & $\begin{array}{c}18-23 \text { weeks } \\
(\mathrm{n}=6)\end{array}$ & $\begin{array}{c}24-29 \text { weeks } \\
(\mathrm{n}=15)\end{array}$ & $\begin{array}{c}30-35 \text { weeks } \\
(\mathrm{n}=24)\end{array}$ & $\begin{array}{c}36-41 \text { weeks } \\
(\mathrm{n}=27)\end{array}$ \\
\hline Fetal weight $(\mathrm{g})$ & $81(23)$ & $427(77)$ & $1022(72)$ & $1915(95)$ & $3183(122)$ \\
Placental weight $(\mathrm{g})$ & $58(6)$ & $141(12)$ & $259(13)$ & $342(16)$ & $442(18)$ \\
IVS volume (ml) & $28(5)$ & $59(7)$ & $119(6)$ & $165(10)$ & $191(9)$ \\
FTF volume (ml) & $0.5(0.1)$ & $1.3(0.3)$ & $2.3(0.3)$ & $2.9(0.5)$ & $5.9(0.9)$ \\
Villous surface $\left(\mathrm{m}^{2}\right)$ & $0.9(0.1)$ & $2.5(0.4)$ & $5.0(0.3)$ & $7.7(0.4)$ & $10.8(0.4)$ \\
Vfib/Vivs $\left(\mathrm{ml} / \mathrm{ml}^{2}\right)$ & $0.018(0.005)$ & $0.022(0.005)$ & $0.020(0.002)$ & $0.017(0.003)$ & $0.032(0.005)$ \\
Vfib/Svilli $\left(\mathrm{ml} / \mathrm{m}^{2}\right)$ & $0.56(0.12)$ & $0.52(0.07)$ & $0.46(0.04)$ & $0.36(0.06)$ & $0.54(0.07)$ \\
\hline
\end{tabular}

Vfib/Vivs represents the volume density of FTF within the IVS and Vfib/Svilli the ratio of FTF volume to villous surface 
Significant differences between altitudes were detected for birthweight (reduced at high altitude; $\mathrm{F}=9.91 ; \mathrm{df}=1,60, \mathrm{P}<0.01$ ), IVS volume (greater at high altitude; $\mathrm{F}=23.92 ; \mathrm{P}<0.001)$, FTF volume (reduced; $\mathrm{F}=8.88 ; \mathrm{P}<0.01$ ), villous surface area (reduced; $\mathrm{F}=8.29 ; \mathrm{P}<0.01$ ) and the volume density of FTF in IVS (reduced; $\mathrm{F}=33.97 ; \mathrm{P}<0.001$ ). Ethnic differences were confined to birthweight (greater in Amerindians; $\mathrm{F}=5.23 ; \mathrm{df}=1.60 ; \mathrm{P}<0.05)$ and no significant interaction terms were detected.

At neither altitude did the amount of FTF in these term placentas show a significant correlation with the volume of IVS. Allometry revealed that FTF volume altered at low altitude according to the relation

$$
\text { Vfib }=2.98 \times 10^{7} \times \text { Vivs }^{0.006(0.014)}
$$

whilst the corresponding relation at high altitude was

$$
\mathrm{Vfib}=1.00 \times 10^{5} \times \mathrm{Vivs}^{0.004(0.009)} .
$$

In contrast, FTF volume demonstrated significant positive correlations with villous surface area at both low altitude $(\mathrm{r}=0.691 ; \mathrm{df}=22 ; \mathrm{P}<0.001)$ and high altitude $(\mathrm{r}=0.520 ; \mathrm{df}=42 ; \mathrm{P}<0.001)$. Corresponding allometric relationships were

$$
\text { Vfib }=1.504 \times \text { Svilli }^{1.21(0.27)}
$$

at low altitude, and

$$
\text { Vfib }=0.723 \times \text { Svilli }^{1.10(0.28)}
$$

at high altitude. Again, the volume of FTF volume seemed to change in a manner dependent more on villous surface than IVS volume.

\section{DISCUSSION}

Present findings suggest that deposition of FTF in the intervillous space of the human placenta is related mainly to the surface area of villi rather than the volume of intervillous space. In placentas examined between 12 weeks of gestation and term, the volume of FTF increased with both the volume of IVS and villous surface area. However, in term placentas from low- and high-altitude pregnancies, differences between IVS and villous relationships were resolved. At both altitudes, no significant correlations between FTF volume and IVS volume were detected but there were significant associations with villous surface. In all cases, FTF volume altered in direct proportion to the changes in villous surface area.

Estimates of the volumes of FTF in normal pregnancies are consistent with those seen in previous studies. Typically, FTF occupies a relatively small volume (2-5\%) of the IVS at term and this amounts to roughly 5-10 $\mathrm{cm}^{3}$ (Laga et al., 1973; Jackson et al., 1987a). Fox (1967b, 1975) proposed that the amount of FTF merely reflects the quality of IVS perfusion. If we take IVS volume as a measure of perfusion, the present findings support this proposal as well as the observations of others which indicate that volumes of IVS and FTF increase throughout gestation (Aherne and Dunnill, 1966; Boyd, 1984). However, there is a disproportionate increase in the amount of FTF near term. This is implicit also in the results of previous studies (see Aherne and Dunnill, 1966; Bhargava et al., 1976; Boyd, 1984) and it indicates that the quality of vascular perfusion is not the only influential factor.

Table 2. Fetal and placental characteristics in low- and high-altitude pregnancies. Values are group means (SEM).

\begin{tabular}{lcccc}
\hline \multirow{2}{*}{ Variable } & \multicolumn{2}{c}{ Low Altitude } & \multicolumn{2}{c}{ High Altitude } \\
\cline { 2 - 5 } & Amerindian $(\mathrm{n}=10)$ & Non-indian $(\mathrm{n}=14)$ & Amerindian $(\mathrm{n}=16)$ & Non-indian $(\mathrm{n}=28)$ \\
\hline Birthweight $(\mathrm{g})$ & $3425(138)$ & $3226(104)$ & $3142(89)$ & $2927(59)$ \\
Placental weight $(\mathrm{g})$ & $460(32)$ & $456(28)$ & $480(17)$ & $454(15)$ \\
IVS volume $(\mathrm{ml})$ & $187(25)$ & $173(10)$ & $256(10)$ & $244(11)$ \\
FTF volume $(\mathrm{ml})$ & $9.2(1.2)$ & $8.0(1.0)$ & $6.9(0.8)$ & $5.6(0.5)$ \\
Villous surface $\left(\mathrm{m}^{2}\right)$ & $6.7(0.7)$ & $7.0(0.6)$ & $6.3(0.3)$ & $5.2(0.2)$ \\
Vfib/Vivs $\left(\mathrm{ml} / \mathrm{ml}^{2}\right)$ & $0.053(0.007)$ & $0.048(0.006)$ & $0.027(0.003)$ & $0.024(0.003)$ \\
Vfib/Svilli $\left(\mathrm{ml} / \mathrm{m}^{2}\right)$ & $1.33(0.09)$ & $1.18(0.13)$ & $1.10(0.11)$ & $1.06(0.07)$ \\
\hline
\end{tabular}


There is evidence from normal pregnancies that haemostatic factors, and hence the coagulationfibrinolysis steady state, vary (Mercelina-Roumans et al., 1996). Especially during the last trimester, the coagulation cascade is stimulated whilst fibrinolytic activity decreases (Shaper et al., 1965; Fletcher et al., 1979; Oliver et al., 1976). This shift in steady state towards coagulation is entirely consistent with the present increase in FTF deposition observed at 36-41 weeks of gestation. The changes probably represent physiological adaptations to help minimise bleeding at the time of placental detachment.

It is also clear that the relationship between FTF and IVS volume does not offer a complete explanation for changes seen in all pregnancies. It is not true in general that FTF deposition occurs less frequently in abnormal pregnancies (Aherne and Dunnill, 1966; Fox, 1967b, 1975; Teasdale, 1984, 1985, 1987; Mayhew et al., 1994; Kaufmann et al., 1996; Mayhew and Sisley, 1998; Mayhew et al., 2000). The present finding confirms that FTF volume is less in high-altitude pregnancies despite the presence of a more voluminous IVS and an increase in the mean volume of its 'pores' (Jackson et al., 1987a; Lee and Mayhew, 1995). These findings suggest that the steady state between coagulation and fibrinolysis in the IVS varies in different pregnancy complications. However, the absolute amount of FTF is influenced also by the available villous surface and this is diminished at high altitude (see also Jackson et al., 1987b).

Changes in haemostatic factors also occur in abnormal pregnancies including those associated with pre-eclampsia (Condie and Ogston, 1976; Kobayashi and Terao, 1987), maternal smoking (Mercelina-Roumans et al., 1996) and type 2 diabetes mellitus (Quinn and Grant, 1999). The reduced FTF content in high-altitude placentas cannot be explained by the changes in IVS volume or the accompanying alteration in the plasma fraction which results from elevated haematocrits (Haas, 1980). This suggests that there is an altered steady state favouring fibrinolysis in the highland placenta.

One possible substrate for promoting the coagulation cascade is the villous surface and, particularly, denuded regions of trophoblastic epithelium. During gestation, and in term organs at low and high altitudes, there are strong associations between FTF deposition and villous surface area. The preferential association of perivillous FTF with damaged areas of trophoblast is well-documented (Fox, 1967a; Nelson et al., 1990; Demir et al., 1997; Mayhew et al., 2000). Damaged epithelium is likely to activate the extrinsic coagulation pathway.

Healthy syncytiotrophoblast is potentially procoagulatory because it externalises phosphatidylserine at its maternal membrane surface during cytotrophoblast fusion and intrasyncytial apoptosis (Huppertz et al., 1998, 1999). Despite these features of normal trophoblast turnover (Mayhew et al., 1999), coagulation does not normally occur across the entire villous surface and this is partly because the placenta produces the anti-coagulant protein annexin- $\mathrm{V}$ which binds to phosphatidylserine (Krikun et al., 1994; Rand et al., 1994; Vogt et al., 1997). Denudation sites may also display apoptotic syncytiotrophoblast nuclei (Nelson, 1996; Ratts et al., 2000). Pre-apoptotic and apoptotic nuclei accumulate in multinucleated syncytial knot regions and are extruded into the maternal circulation as part of continuous epithelial replacement (Huppertz et al., 1998; Mayhew et al., 1999). These observations prompted us to suggest that some sites of de-epithelialisation with FTF deposits may arise following the extrusion of syncytial trophoblast fragments into the intervillous space (Mayhew et al., 2000).

Other factors in the trophoblast, or at its surface, may also influence haemostasis. For instance, nitric oxide inhibits platelet activation and the trophoblastic syncytium contains the endothelial isoform of nitric oxide synthase, levels of which fall during the last trimester (Ramsay et al., 1996; Lyall et al., 1998). The plasminogen activators convert inactive plasminogen into plasmin, the key fibrinolytic enzyme. The urokinase plasminogen activator (uPA) and its receptor (uPAR) have been implicated in trophoblast repair and FTF surveillance (Pierleoni et al., 1998). Normal trophoblast expresses uPA and uPAR (Hofmann et al., 1994; Multhaupt et al., 1994) and the latter may be associated with FTF deposition sites (Pierleoni et al., 1998).

\section{ACKNOWLEDGEMENTS}

I am grateful to The Wellcome Trust, Medical Research Council (Development Grant Scheme), British Heart Foundation and Special Trustees of Nottingham University Hospitals for supporting my placental and stereological studies. I also thank Drs Boyd (Oxford), Haas (Cornell) and Rusu (neé Jackson, Toronto) for their help in collecting placental material. 


\section{REFERENCES}

Aherne W, Dunnill MS (1966). Quantitative aspects of placental structure. J Pathol Bacteriol 91:123-39.

Baddeley AJ, Gundersen HJG, Cruz-Orive LM (1986). Estimation of surface area from vertical sections. J Microsc 142:259-76.

Bhargava I, Kamashki K, Dodge Y (1976). A morphometric study of human placentae of different gestational ages from normal and triplet pregnancies. Natl Bureau Stand Publ 431:405-8.

Boyd PA (1984). Quantitative structure of the normal human placenta from 10 weeks of gestation to term. Early Human Dev 9:297-307.

Brownbill P, Mahendran D, Owen D, Swanson PS, Thornburg KL, Nelson DM, Sibley C (2000). Denudations as paracellular routes for alphafetoprotein and creatinine across the human syncytiotrophoblast. Am J Physiol, Regul Integr Comp Physiol 278:R677-83.

Condie RG, Ogston D (1976). Sequential studies on components of the haemostatic mechanism in pregnancy with particular reference to the development of preeclampsia. Br J Obstet Gynaecol 83:938-42.

Demir R, Kosanke G, Kohnen G, Kertschanska S, Kaufmann P (1997). Classification of human placental stem villi: review of structural and functional aspects. Microsc Res Technique 38:29-41.

Fletcher AP, Alkjaersi NK, Burstein R (1979). The influence of pregnancy upon blood coagulation and plasmin fibrinolytic enzyme function. Am J Obstet Gynecol 134:743-51.

Fox H (1967a). Perivillous fibrin deposition in the human placenta. Am J Obstet Gynecol 98:245-51.

Fox $H$ (1967b). The significance of placental infarction in perinatal morbidity and mortality. Biol Neonate 11:87-105.

Fox H (1968). Fibrinoid necrosis of placental villi. J Obstet Gynaecol Br Commonwealth 75:448-52.

Fox H (1975). Morphological pathology of the placenta. In: Gruenwald P, ed. The placenta and its maternal supply line: effects of insufficiency on the fetus. Lancaster: Medical Technical Publications, 197-220.

Frank H-G, Malekzadeh F, Kertschanska S, Crescimanno C, Castellucci M, Lang I, Desoye G, Kaufmann P (1994). Immunohistochemistry of two different types of placental fibrinoid. Acta Anat 150:55-68.

Gundersen HJG, Jensen EB (1987). The efficiency of systematic sampling in stereology and its prediction. $\mathbf{J}$ Microsc 147:229-63.

Haas JD (1980). Maternal adaptation and fetal growth at high altitude in Bolivia. In: Greene LS, Johnston FS, eds. Social and biological predictors of nutritional status, physical growth and neurological development. New York: Academic Press, 257-90

Hofmann GE, Glatstein I, Schatz F, Heller D, Deligdsch L (1994). Immunohistochemical localization of urokinase- type plasminogen activator and the plasminogen activator inhibitors 1 and 2 in early human implantation sites. Am J Obstet Gynecol 170:671-6.

Howard CV, Reed MG (1998). Unbiased stereology. Threedimensional measurement in microscopy. Oxford: Bios Scientific.

Huppertz B, Frank H-G, Kaufmann P (1999). The apoptosis cascade - morphological and immunohistochemical methods for its visualization. Anat Embryol 200:1-18.

Huppertz B, Frank H-G, Kingdom JCP, Reister F, Kaufmann P (1998). Villous cytotrophoblast regulation of the syncytial apoptotic cascade in the human placenta. Histochem Cell Biol 110:495-508.

Jackson MR, Mayhew TM, Haas JD (1987a). The volumetric composition of human term placentae: altitudinal, ethnic and sex differences in Bolivia. J Anat 152:173-87.

Jackson MR, Mayhew TM, Haas JD (1987b). Morphometric studies on villi in human term placentae and the effects of altitude, ethnic grouping and sex of newborn. Placenta 8:487-95.

Jackson MR, Mayhew TM, Boyd PA (1992). Quantitative description of the elaboration and maturation of villi from 10 weeks of gestation to term. Placenta 13:357-70.

Kaufmann P, Huppertz B, Frank H-G (1996). The fibrinoids of the human placenta: origin, composition and functional relevance. Annals Anat 178:485-501.

Kobayashi T, Terao T (1987) Preeclampsia as chronic disseminated intravascular coagulation. Study of two parameters: thrombin-antithrombin III complex and Ddimers. Gynecol Obstet Invest 24:170-8.

Krikun G, Lockwood CJ, Wu X-X, Zhou X-D, Guller S, Calandri C, Guha A, Nemerson Y, Rand JH (1994). The expression of the placental anticoagulant protein, annexin $\mathrm{V}$, by villous trophoblasts: immunolocalization and in vitro regulation. Placenta 15:601-12.

Laga EM, Driscoll SG, Munro HN (1973). Quantitative studies of human placenta. I. Morphometry. Biol Neonate 23:23159.

Lang I, Hartmann M, Blaschitz A, Dohr G, Kaufmann P, Frank H-G, Hahn T, Skofitsch G, Desoye G (1994). Differential lectin binding to the fibrinoid of human full-term placenta: correlation with a fibrin antibody and the PAF-Halmi method. Acta Anat 150:170-7.

Lee R, Mayhew TM (1995). Star volumes of villi and intervillous pores in placentae from low and high altitude pregnancies. J Anat 186:349-55.

Lyall F, Jablonka-Shariff A, Johnson RD, Olson LM, Nelson MD (1998). Gene expression of nitric oxide synthase in cultured human term placental trophoblast during in vitro differentiation. Placenta 19:253-60.

Mattfeldt T, Mall G, Gharehbaghi H, Möller P (1990). Estimation of surface area and length with the orientator. J Microsc 159:301-17. 
Mayhew TM, Burton GJ (1988). Methodological problems in placental morphometry: apologia for the use of stereology based on sound sampling practice. Placenta 9:565-81.

Mayhew TM, Bowles C, Orme G (2000). A stereological method for testing whether or not there is random deposition of perivillous fibrin-type fibrinoid at the villous surface: description and pilot applications to term placentae. Placenta 21:684-92.

Mayhew TM, Leach L, McGee R, Wan Ismail W, Myklebust R, Lammiman MJ (1999). Proliferation, differentiation and apoptosis in villous trophoblast at 13-41 weeks of gestation (including observations on annulate lamellae and nuclear pore complexes). Placenta 20:407-22.

Mayhew TM, Sisley I (1998). Quantitative studies on the villi, trophoblast and intervillous pores of placentae from women with well-controlled diabetes mellitus. Placenta 19:371-7.

Mayhew TM, Sørensen FB, Klebe JG, Jackson MR (1994). Growth and maturation of villi in placentae from wellcontrolled diabetic women. Placenta 15:57-65.

Mercelina-Roumans PEAM, Ubachs JMH, van Wersch JWJ (1996). Coagulation and fibrinolysis in smoking and nonsmoking pregnant women. Br J Obstet Gynaecol 103:789-94.

Multhaupt HAB, Mazar A, Cines DB, Warhol MJ, McCrae KR (1994). Expression of urokinase receptors by human trophoblast. A histochemical and ultrastructural analysis. Lab Invest 71:392-400.

Nelson DM (1996). Apoptotic changes occur in syncytiotrophoblast of human placental villi where fibrin type fibrinoid is deposited at discontinuities in the villous trophoblast. Placenta 17:387-91.

Nelson DM, Crouch EC, Curran EM, Farmer DR (1990). Trophoblast interaction with fibrin matrix. Epithelialization of perivillous fibrin deposits as a mechanism for villous repair in the human placenta. Am J Pathol 136:855-65.

Nyengaard JR, Gundersen HJG (1992). The isector: a simple and direct method for generating isotropic, uniform random sections from small specimens. J Microsc 165:427-31.

Oliver RD, Patterson BB, Puls JL (1976). Thrombin clottable determination of plasma fibrinogen in pregnancy. Obstet Gynecol 47:299-303.

Pierleoni C, Samuelsen GB, Graem N, Rønne E, Nielsen BS, Kaufmann P, Castellucci M (1998). Immunohistochemical identification of the receptor for urokinase plasminogen activator associated with fibrin deposition in normal and ectopic human placenta. Placenta 19:501-8.

Quinn ND, Grant PJ (1999). Fibrinolysis and type 2 diabetes mellitus. Pract Diabetes Intern 16:255-8.

Ramsay B, Soorana SR, Johnson MR (1996). Nitric oxide synthase activities in human myometrium and villous trophoblast throughout pregnancy. Obstet G ynecol 87:249-53.

Rand JH, Wu X-X, Guller S, Gil J, Guha A, Scher J, Lockwood CJ (1994). Reduction of annexin-V (placental anticoagulant protein I) on placental villi of women with antiphospholipid antibodies and recurrent spontaneous abortion. Am J Obstet Gynecol 171:1566-72.

Ratts VS, Tao X-J, Webster CB, Swanson PE, Smith SD, Brownbill P, Krajewski S, Reed JC, Tilly JL, Nelson DM (2000). Expression of BCL-2, BAX and BAK in the trophoblast layer of the term human placenta: a unique model of apoptosis within a syncytium. Placenta 21:361-6.

Shaper AG, Macintosh DM, Evans CM, Kyobe J (1965). Fibrinolysis and plasminogen levels in pregnancy and the puerperium. Lancet 2:706-8.

Sokal RR, Rohlf FJ (1981). Biometry. The principles and practice of statistics in biological research. San Francisco: W.H. Freeman.

Teasdale F (1984). Idiopathic intrauterine growth retardation: histomorphometry of the human placenta. Placenta 5:83-92.

Teasdale F (1985). Histomorphometry of the human placenta in maternal preeclampsia. Am J Obstet Gynecol 152:25-31.

Teasdale F (1987). Histomorphometry of the human placenta in pre-eclampsia associated with severe intrauterine growth retardation. Placenta 8:119-28.

Vogt E, Ng A-K, Rote NS (1997). Antiphosphatidylserine antibody removes annexin- $\mathrm{V}$ and facilitates the binding of prothrombin at the surface of a choriocarcinoma model of trophoblast differentiation. Am J Obstet Gynecol 177:964-72. 